U. D.C. 577.164 .11

33. 渡辺 厚, 朝日 豊：ビタミン $\mathrm{B}_{1}$ とその関連物質の物理化学的研究（第 5 報*) ビタミン $\mathrm{B}_{1}$ のアルカリ性水溶液に和ける変化**

Atsushi Watanabe and Yutaka Asahi: Physicochemical Studies of Vitamin $\mathrm{B}_{1}$ and its Related Compounds. V. Decomposition of Thiamine in Alkaline Solution.

(Research Laboratory, Takeda Pharmacentical Industries, Ltd.***)

When alkaline aqueous solution of thiamine (I) is allowed to stand in contact with air at $25^{\circ}$, oxidation of the thiol-type thiamine (III) chiefly occurs. Thiamine disulfide (IV), bis (1-acetyl-3-hydroxypropyl) disulfide (X), and 3-mercaptopropanol (XI) formed in this case were followed by polarography and the formation of thiothiazolone compound (VI) was measured by the optical density at $320 \mathrm{~m} \mu$ (cf. Tables I and II). For example, percentage composition of the sample solution after 146 hours was as follows : At pH 9.3 : (I) 15, (IV) 65, (VI) 10, (XI) 1.3; at pH 104 (I) 14, (IV) 35 , (VI) 11 , (XI) 8.3 ; at pH $12.0:$ (I) 25 , (IV) 13 , (VI) 11.5 , (XI) 17 . When the same solution is allowed to stand in nitrogen atmosphere at $25^{\circ}$ or heated to $100^{\circ}$, hydrolysis of the thiazole portion of thiamine chiefly occurs, forming (X), (XI), (VI), and 3-acetyl-3-mercaptopropanol, and this was similarly measured. For example, the percentage composition of the sample solution left in nitrogen atmosphere at $25^{\circ}$ for 146 hours was as follows : at pH 9.3 : (I) 48 , (IX) 13, (VI) 11 ; at pH 10.4 : (I) 20, (IX) 20, (VI) 20; at pH 12 : (I) 49, (IX) 4.7, (VI) 15, (XI) 3.6.

(Received September 20, 1956)

渡辺ら1) はビタミン $\mathrm{B}_{1}$ (以下 $\mathrm{B}_{1}$ と略記) のアルカリ性の分解によつて thiothiazolone 化合物が生成するこ

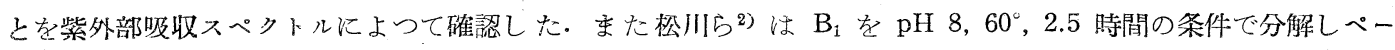
パークロマトグラフィーで thiochrome (VIII), $\mathrm{B}_{1}$ disulfide (IV), $\mathrm{B}_{1}$ thiazolone (VII), $\mathrm{B}_{1}$ thiothiazolone (VI) などを検出した。これらはいずれもアルカリ性に和けるチオール型 $\mathrm{B}_{1}$ の変化と見られる。

著者らはこの報告でチオール型 $\mathrm{B}_{1}$ の変化を定量的に明らかにするために種々の試みを行つた。その結果チオ 一ル型 $\mathrm{B}_{1}$ の锩気的分解以よつて 3-acetyl-3-mercaptopropanol (IX)，3-mercaptopropanol (XI) 扰よびそれ らの disulfide (X) などが生成すること, 空気中に抒いては主として $\mathrm{B}_{1}$ disulfide (VI) が生成し (IX), (X) が 副生することなどをポーラログラフ法によつて観察し，さらに吸収スペクトル，チオクローム反応，電位差滴定 法などを併用しご水らの变化の定量的な関係を求めた。

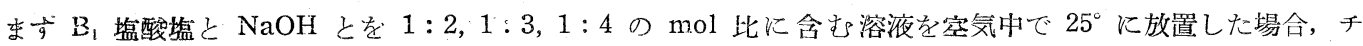
オクローム区応による $\mathrm{B}_{1}$ の定量値は急速に低下し, 同時に 245 抢よび $265 \mathrm{~m} \mu$ に拈るる吸取が僅かに低下し, $320 \mathrm{~m} \mu$ に把々 thiothiazolone 化合物の吸収は初め急に増大するが後には緩徐になりほぼ一定值に達する。

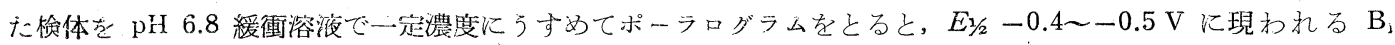
disulfide の還元波 ${ }^{3}(\mathrm{C})$ は $\mathrm{B}_{1}$ の定量值の低下につれて増大してくる.アルカリの裖度が高い場合は生じた $\mathrm{B}_{1}$ disuifide が分解し (C) の睘元波は漸炏低下し，3-mercaptopropanol (XI) に起因すると考えられる $E_{1 / 2}-0.14$ $\mathrm{V}$ の陽極波 (A) が増大する。この他 bis (1-acetyl-3-hydroxypropyl) disulfide (X) に起因すると思われる $E_{1 / 2}$ -0.58 V の還元波 (D), bis(3-hydroxypropyl) disulfide によると思われる $E_{3 / 2}-0.7 \mathrm{~V}$ の還元波 (E) などが 誌められる.千オクローム法による $\mathrm{B}_{1}$ の定量值の減少速度は $\mathrm{B}_{1}$ 塩酸塩 : $\mathrm{NaOH}$ の比が $1: 3$ の溶液の場合が

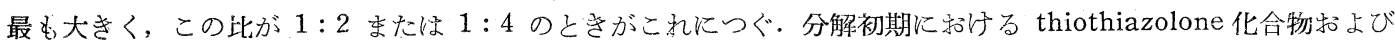
B: disulfide などの生成速度も $\mathrm{B}_{\mathrm{i}}$ とアルカリの比が $1: 3$ の場合に最大であつた (Fig. 2, Table I, II).

* 第 4 報：本誌 75, 1050(1955)。 **ビタミン B 総合研究委員会に発表. ビタミン 5, 402, 412(1952), *** Juso-nishino-cho, Higashiyodogawa-ku, Osaka.

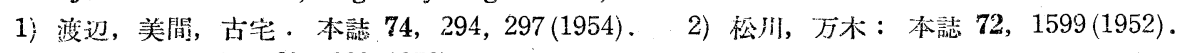

3) 館, 小出 : 農化 $25,330(1952)$. 
以上の結果から空気中に括惊る $\mathrm{B}_{1}$ の分解はチォール型 $\mathrm{B}_{1}$ の平衡濃度が高いとき程大きく, 主として $\mathrm{B}_{1}$ disulfide に酸化され一部はアルカリによつて加水分解し (V), (IX) 拈よび義酸に変化し，(IX) はさらに (X), (XI) などに変化すると結論される. 山内4) はチォール型 $B_{1}$ が $B_{1}$ disulfide 酸化される状態を Warburg 検 生法によつて研究し，アルカリ濃度が高い程酸素消費量が大きいと報告しているが，著者らの奏験ではアルカリ 濃变が高い場合 $\mathrm{B}_{1}$ disulfide が 2 次的分解を起すため, アルカリ濃度がある程度低い方が分解後期の $\mathrm{B}_{1}$ disulfide 生成量が多かつた。また $\mathrm{B}_{1}$ から thiothiazolone 化合物が生成する機構はまだ明白ではないが，その $\mathrm{S}$ 供給源 として $(\mathrm{IX})$ （XI) のような含硫化合物が考えられる.

つぎに著者らは $\mathrm{B}_{1}$ とアルカリを種々の割合に混合した前述の検液を $\mathrm{N}_{2}$ ガス中で $25^{\circ} に$ 保存した場合の变化 を同様の方法で研究した (Fig. 1, Table I，II)。この場合チオクローム法による $\mathrm{B}_{1}$ の定量值の減少速度は空気 中のときよりもいく分遲くなり，thiothiazolone 化合物の生成速度は最初空気中のときより小さいが後には次第 に大きくなり，この間ピリミジンの吸収には大きな変化がなかつた。ポーラログラムでは $B_{1}$ disulfide の還元波 が全く認められず，主としてチ才一ル型 $\mathrm{B}_{1}$ の加水分解が起り 3-acetyl-3-mercaptopropanol (IX) の陽極波 (B) 特よび (D)，(E) など disulfide 体の還元波が見られ $\mathrm{B}_{1}$ の定量値が減少するにつれてこれらの波は增大した. 検 渡を空気中に放置すると（B）波はなくなり沈澱が生成し，アルカリ濃度が高い埸合は (IX)の 2 次的分解によつ て 3-mercaptopropanol (XI) によると思われる陽極波 (A) が熟められる.

つぎに $\mathrm{B}_{1}$ のアルカリ性水溶液を $100^{\circ}$ に加熱した場合は空気の有無にかかわらずほ夙㥞に分解し, 主とし

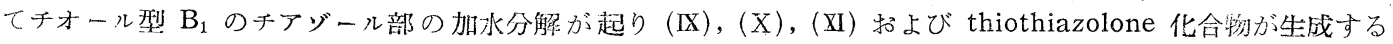
(Fig. 3, Table II).

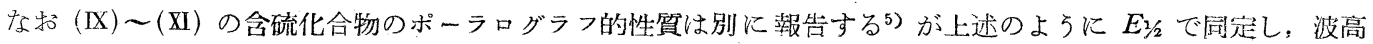

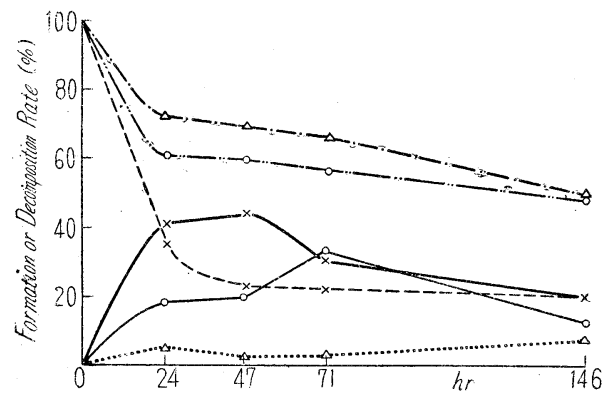

Fig. 1. Decomposition Rate of Thiamine determined by Thiochrome Reaction (upper curves) and Formation Rate of 3-Acetyl-3mercaptopropanol observed by Anodic Wave (lower curves) after Standing of the Solution (thiamine : $\mathrm{NaOH} 1: 2(\bigcirc), 1: 3(\times), 1: 4$ $(\triangle))$ at $25^{\circ}$ in $\mathrm{N}_{2}$ Atmosphere

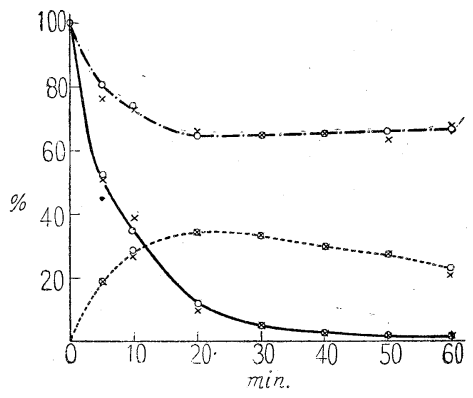

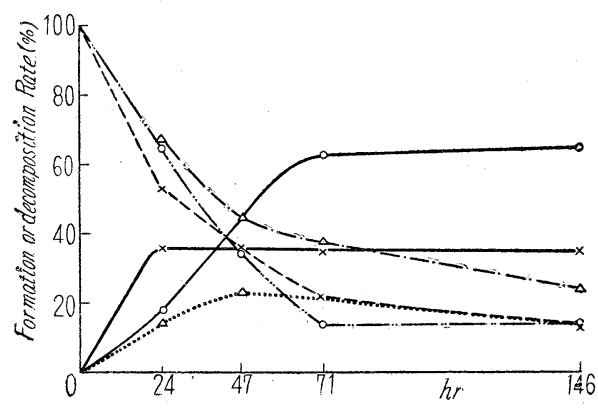

Fig 2. Decomposition Rate of Thiamine (upper curves)and Formation Rate of Thiamine Disulfide observed by Reduction Wave (lower curves) after Standing of the same Solution as in Fig. 1 at $25^{\circ}$ in Air

Fig. 3.

Decomposition Rate of Thiamine observed by Thiochrome Reaction (-) and Optical Density at $245 \mathrm{~m} \mu(--)$ ) and Formation Rate of $\mathrm{B}_{1}$-thiothiazolone (VI) observed by Optical Density at $320 \mathrm{~m} \mu$ at $\mathrm{pH} 2.7(---$.$) ) after$ Treatment of the Solution (thiamine: $\mathrm{NaOH}=$ $1: 4, \mathrm{pH} 12)$ at $100^{\circ}$ in $\mathrm{N}_{2}(\bigcirc)$ or air $(x)$

4) 山内：ビタミン 7, 261(1954).

5) 朝日：薬品のポーラログラフ的研究第 10 報 およびその続報. 
Table I. Decomposition Rate of Thiamine (Vitamin $B_{1}$ ) determined by Thiochrome Reaction and the Absorption at $320 \mathrm{~m} \mu$ and $245 \mathrm{~m} \mu$ at $\mathrm{pH} 2.7$ after Standing of the Alkaline Solution of $\mathrm{B}_{1}$ at $25^{\circ}$ in Air or $\mathrm{N}_{2}$ Atmosphere

\begin{tabular}{|c|c|c|c|c|c|c|c|c|}
\hline Atmosphe & ere & $\mathrm{N}_{2}$ & $\mathrm{~N}_{2}$ & $\mathrm{~N}_{2}$ & Air & Air & Air & \\
\hline $\mathrm{NaOH} / \mathrm{B}_{1}$ & & 2 & 3 & 4 & 2 & 3 & 4 & 0 \\
\hline $\mathrm{pH}$ & $h r$ & 9.3 & 10.4 & 12.0 & 9.3 & 10.4 & 12.0 & 3. 0 \\
\hline $\begin{array}{l}\text { Thiochrome } \\
\text { reaction } \%\end{array}$ & $\begin{array}{r}24 \\
47 \\
71 \\
146\end{array}$ & $\begin{array}{l}60.8 \\
60.3 \\
55.8 \\
47.8\end{array}$ & $\begin{array}{l}40.6 \\
23.0 \\
22.0 \\
19.6\end{array}$ & $\begin{array}{l}72.5 \\
70.2 \\
66.7 \\
49.3\end{array}$ & $\begin{array}{l}65.2 \\
36.1 \\
14.2 \\
14.9\end{array}$ & $\begin{array}{l}53 \\
36.9 \\
22.0 \\
14.1\end{array}$ & $\begin{array}{l}66.5 \\
44.8 \\
38.4 \\
25.1\end{array}$ & $\begin{array}{r}100 \\
\text { /" } \\
\text { " } \\
\text { " }\end{array}$ \\
\hline
\end{tabular}

$\varepsilon \cdot 10^{-4} \quad\left(\begin{array}{lllllll}24 & 1.343(96.7) & 1.239(89.1) & 1.306(94.0) & 1.316(94.7) & 1.270(91.4) & 1.353(97.3)\end{array}\right.$

$(245 \mathrm{m \mu})\left\{\begin{array}{llllllll}47 & 1.278(92.0) & 1.220(87.8) & 1.302(93.6) & 1.314(94.5) & 1.314(94.5) & 1.316(94.6) & 1.390(100)\end{array}\right.$

$(\%) \quad \begin{array}{rllllllll}71 & 1.249(89.8) & 1.203(86.6) & 1.283(92.3) & 1.280(92.0) & 1.284(92.3) & 1.290(93.8) & 1.375(99)\end{array}$

(\%) $\quad \begin{array}{lllllllll}146 & 1.278(92.0) & 1.138(82.8) & 1.212(87.2) & 1.274(91.7) & 1.220(87.7) & 1.230(88.4) & 1.386(99.6)\end{array}$

$\varepsilon \cdot 10^{-4} \quad\left(\begin{array}{cccccccc}24 & 0.048(4.8) & 0.063(6.3) & 0.047(4.7) & 0.054(5.4) & 0.067(6.7) & 0.061(6.1) & 0.010\end{array}\right.$

$(320 \mathrm{~m} \mu)\left\{\begin{array}{llllllll}47 & 0.058(5.8) & 0.088(8.8) & 0.078(7.8) & 0.085(8.5) & 0.084(8.4) & 0.075(7.5) & 0.012 \\ 71 & 0.078(7.8) & 0.122(12.2) & 0.104(10.4) & 0.097(9.7) & 0.098(9.8) & 0.089(8.9) & 0.013\end{array}\right.$

$(\%) * \quad \begin{array}{rllllllll}71 & 0.078(7.8) & 0.122(12.2) & 0.104(10.4) & 0.097(9.7) & 0.098(9.8) & 0.089(8.9) & \prime \prime \\ 146 & 0.106(10.6) & 0.196(19.6) & 0.150(15.0) & 0.100(10.0) & 0.111(11.1) & 0.115(11.5) & 0.013\end{array}$

* Formation rate of thiothiazolone compounds calculated as $B_{1}$-thiothiazolone $(\varepsilon=10000)$

Table II. Formation Rate (\%) of 3-Mercaptopropanol (anodic wave, $E_{y / 2}-0.14 \mathrm{~V}: \mathrm{A}$ ), 3-Acetyl-3-mercaptopropanol (anodic wave, $\left.E_{1 / 2}-0.36 \mathrm{~V}: \mathrm{B}\right)$, Thiamine Disulfide (cathodic wave, $E_{2 / 2}-0.4 \sim-0.5 \mathrm{~V}: \mathrm{C}$ ) and some Disulfides (cathodic wave,

$\left.E_{3 / 2}-0.58 \mathrm{~V}: \mathrm{D}, E_{3 / 2}-0.70 \mathrm{~V}: \mathrm{E}\right)$ in the Course of Alkali Decomposition of Thiamine at $25^{\circ}$ or $100^{-}$observed by Wave Height $(\times 0.0142 \mu \mathrm{A})$ in a Solution $(\mathrm{pH} 6.8$,

initial Concentration of Thiamine $2 \mathrm{mM})$ at $25^{\circ} \quad\left(\mathrm{m}^{2 / 3 \mathrm{t}^{1} / 6}=1.127\right)$

\section{Condition of treatment}

Atmos- Temp.Time.

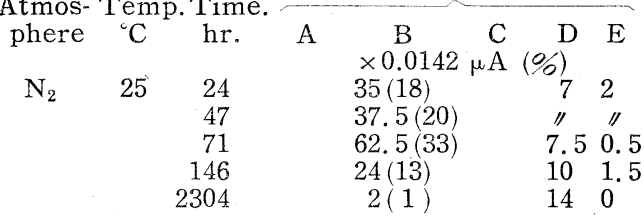

3: 1 $(\mathrm{pH} 10.4)$
$4: 1$ $(\mathrm{pH} 12.0)$

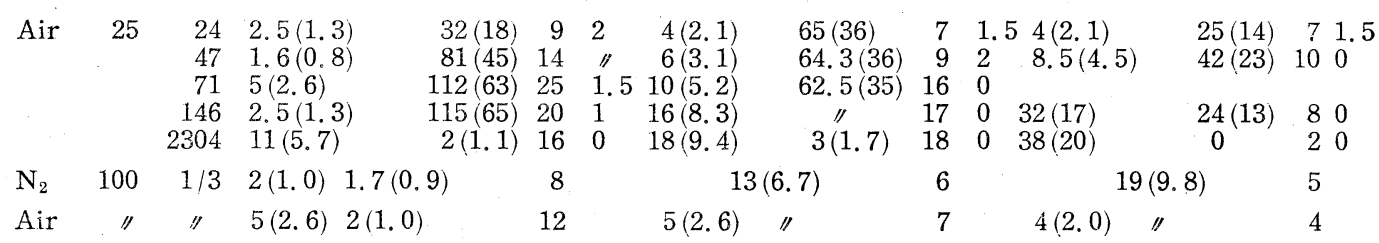

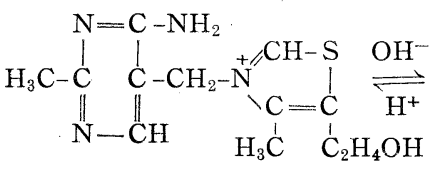

( I )

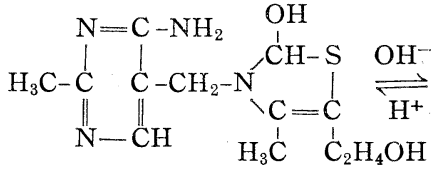

(II)

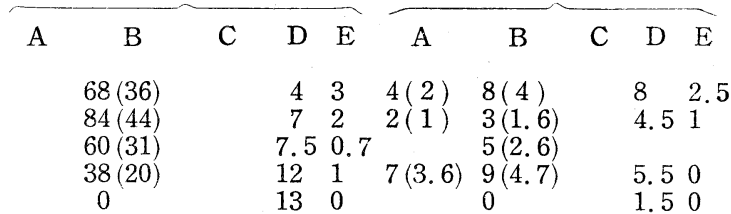<smiles>CC1N=CC(CN(C=O)C(C)C(S)CO)C(N)=N1</smiles><smiles>[Mg][Mg][Mg]</smiles>

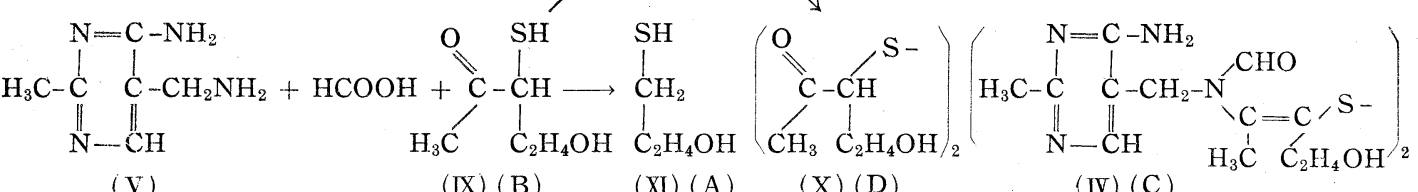

(V)<smiles>CCC1(C)N(Cc2cnc(C)nc2N)C(=S)SC1(C)CO</smiles>

(IX) (B)<smiles>Cc1ncc(CN2C(=O)SC(CO)C2(C)C)c(N)n1</smiles>

(IV) (C)<smiles>CC1=C(CCO)SC2=Nc3nc(C)ncc3CN21</smiles> 
で定量することができる・また（IX)，(XI）の陽極波 (B)，(A) は p-chloromercuribenzoate によつて抑制され ることからもこれがチオール化合物で晾ることがわかる。また $\mathrm{B}_{1}$ のアルカリ分解に特いてピリミジン部の分解 が殆んど認められないことは 245 特よび $265 \mathrm{m \mu}$ の吸収が大して変化しないこと, チアゾール部の開環にともな 弓 $\mathrm{pH}$ 7〜11 のアルカリ消費量が殆んどなくなつても $\mathrm{pK}_{a} 5.7$ を示すピリミジン部のアミン塩酸壏のアルカリ 消蒷量が变化しないことによつて確められた.

終りに本研究に際し終始御指尊御激励を賜わつた所長桑田 智博士に謱謝し吸取测定の労をとられた備中氏に感 謝する。

\section{実 験 の 部}

吸収スペクトルの測定＼cjkstart吸取スペクトルは検体に $\mathrm{HCl}$ を加えて $\mathrm{pH} 2.7$ の $10^{-4} \mathrm{Ni}_{i}$ 溶液とし $1 \mathrm{~cm}$ の液層 に入れ Beckman DU spectrophotometer で測定. thiothiazolone の生成率は $320 \mathrm{~m} \mu$ の吸光係数と $\mathrm{SB}_{1}$ の $320 \mathrm{~m} \mu$ の分子吸光俰数 $\varepsilon=10000$ とから計算.

$\mathbf{B}_{1}$ の定量 吸取测定に明いた検液 $0.1 \mathrm{cc}$ をとり常法によつてチオクローム反応を行い $\mathrm{B}_{1}$ を定量. $\mathrm{B}_{1}$ の残 存率は $\mathrm{B}_{1}$ の標準溶液を同様に処理したものを $100 \%$ とて計算.

ポーラログラフィー 検体を $\mathrm{pH} 6.8$ リン侄塩緩衝溶液で $2 \cdot 10^{-3} M$ の湄度にうすめ, $25^{\circ} \pm 0.1^{\circ}$ で $\mathrm{m}=0.877$

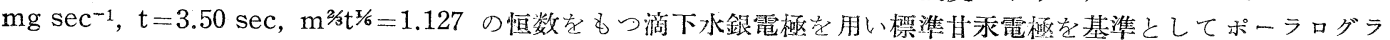
ふをとつた～ $\mathrm{B}_{1}$ disulfide の生成率は $\mathrm{B}_{1} 2 \cdot 10^{-3} M$ から $\mathrm{B}_{1}$ disulfide $1 \cdot 10^{-3} M$ が生成した場合を $100 \%$ と， $E_{1 / 2}-0.4$ 〜 $0.5 \mathrm{~V}$ (濃慶によつて珙なる) の波高から計算 $(179 \times 0.0142 \mu \mathrm{A}$ が $100 \%$ に相当).

PCMB によるチオール化合物の定量 $\mathrm{B}_{1}$ 塩䧈塩と $\mathrm{NaOH}$ を $1: 4$ の $\mathrm{mol}$ 比に含む溶液を $100^{\circ}$ に 20 分 加熱後 $2 \cdot 10^{-3} M, \mathrm{pH} 6.8$ の溶液としポーラログラムをとると $E_{1 / 2}^{1 / 2}-0.14 \mathrm{~V}$ (A) $(-4 \times 0.0142 \mu \mathrm{A}), E_{1 / 2}-036$ $\mathrm{V}(\mathrm{B})(-19 \times 0.0142 \mu \mathrm{A})$ の陽極波および $E_{1 / 2}-0.58 \mathrm{~V}$ (D) $(4 \times 0.0142 \mu \mathrm{A})$ の還元波を得. この溶液 $5 \mathrm{cc} k$ $\mathrm{PCMB} 2 \cdot 10^{-3} M$ 溶液を $0.6 \mathrm{cc}$ 加えると陽極波はちようどなくなり新しく $E_{1 / 2}-0.6 \mathrm{~V}(\mathrm{~F})$ およびー0.85 V $(\mathrm{G})$ の還元波が認められる。このことから (A)，(B) の陽極波は $\mathrm{SH}$ 化合物であることがわかる。また $(\mathrm{F}),(\mathrm{G})$ は $\mathrm{PCMB}$ と $\mathrm{R}^{\prime} \mathrm{SH}$ との反応成績侭 $\mathrm{RHg} \cdot \mathrm{SR}^{\prime}$ の睘元波である.さらに $\mathrm{PCMB}$ を加えると $E_{1 / 2}-0.14 \mathrm{~V}$ に $\mathrm{PCMB}$ の第 1 段還元波が現われ，第 2 段還元波である $(\mathrm{G})$ 波が増加する.また $E_{1 / 2}-0.16 \mathrm{~V}(-42 \times 0.0142 \mu \mathrm{A})$ の陽 極波を示す他の検液は同量の $\mathrm{PCMB} 4.4 \cdot 10^{-4} M$ 老消費. そこで $2 \cdot 10^{-3} M$ の SH 化合物が $-190 \times 0.0142 \mu \mathrm{A}$ の陽極波を示すことになり $\mathrm{B}_{1} 2 \cdot 10^{-3} M$ から SH 化合物 $2 \cdot 10^{-3} M$ が生成した場合を $100 \%$ とて SH 化合 物の生成率を計算.

$\mathbf{B}_{1}$ のアルカリ分解産物の電位差滴定 $\quad \mathrm{B}_{1}$ と $\mathrm{NaOH}$ を $1: 3$ の mol 比に含む溶液を $\mathrm{N}_{2}$ 中で $100^{\circ}, 30$ 分 加熱後 $\mathrm{HCl}$ で中和しさらに $0.1 \mathrm{~N} \mathrm{NaOH} て ゙$ 電位差滴定した結果，第1段 $\left(\mathrm{pK}_{a} 5.7\right)$ には $2.3 \mathrm{cc}$ を要し第 2 段 ( $\mathrm{pH} 7$ ～11) には $0.5 \mathrm{cc}$ を要し $\mathrm{B}_{1}$ と同じく平衡に達するのに数分間要した。加熱前には同じ条件で第 1 , 第 2 段にそれぞれ $0.1 \mathrm{~N} \mathrm{NaOH} 2.1$ および $4.2 \mathrm{cc}$ を要した。第 3 報で述べたように第 1 段は $4^{\prime}$ 位のアミノ基に， 第 2 段はチアゾールの開環に起因する。このことから $\mathrm{B}_{1}$ のチアゾール部が殆んど分解してもピリミジン部のア ミノ基は変化しないことがわかる。 